\title{
Coeficientes de digestibilidade aparente da energia e proteína da silagem de sorgo com alto e baixo tanino pela tilápia do nilo (Oreochromis niloticus)
}

\author{
Apparent digestibility coefficients of energy and protein of low and high tannin \\ silage sorghum for nile tilapia (Oreochromis niloticus)
}

\section{Wilson Massamitu Furuya ${ }^{1}$ Lilian Carolina Rosa Silva ${ }^{2}$ Patrícia Ribeiro Neves $^{2}$ Daniele Botaro ${ }^{2}$ Carmino Hayashi ${ }^{3}$ Antônio Cláudio Furlan ${ }^{1}$ Vivian Gomes dos Santos ${ }^{2}$}

\section{RESUMO}

Este estudo foi realizado para determinar o coeficiente de digestibilidade aparente (CDA) da energia bruta e proteína bruta da silagem de sorgo de baixo tanino (SSBT) e da silagem de sorgo de alto tanino (SSAT) para a tilápia do Nilo (Oreochromis niloticus). A ração referência foi misturada aos ingredientes-teste na proporção de 60:40. Os peixes $(53,26 \pm 12,94 \mathrm{~g})$ foram alimentados até a saciedade aparente e as fezes foram coletadas após sedimentação. A fibra em detergente neutro foi utilizada como indicador endógeno. Os CDA da energia bruta e proteína bruta da SSBT e SSAT variaram entre 70,17 e 68,37\% e 84,94 e 82,40\%, respectivamente. Os valores de energia digestivel foram de 3049,81 e 2954,74kcal $\mathrm{kg}^{-1}$ para SSBT e SSAT, respectivamente. A SSBT apresentou valores significativamente $(P<0,05)$ maiores de energia e proteína digestiveis em relação ao SSAT. Os resultados indicaram que a tilápia do Nilo pode utilizar a energia bruta $e$ proteína bruta da silagem de sorgo eficientemente.

Palavras-chave: digestibilidade aparente, silagem de sorgo, tilápia do Nilo, tanino.

\section{ABSTRACT}

This study was carried out to determine the apparent digestibility coefficients $(A D C)$ of gross energy and crude protein of low tannin silage sorghum (LTSS) and high tannin silage sorghum (HTSS) for Nile tilapia (Oreochromis niloticus). The reference diet was mixed with test ingredients in a 60:40 ratio. Fish $(53.26 \pm 12.94 \mathrm{~g})$ were fed to apparent satiation and faeces were collected other sedimentation The neutral detergent fiber was used as an endogenous indicator. ADC for gross energy and crude protein of LTSS and HTSS varied between 70.17 and $68.37 \%$ and 84.94 and $82.40 \%$, respectively. Digestible energy values were 3,049.81 and 2,954.74kcal $\mathrm{kg}^{-1}$ for LTSS and HTSS, respectively. LTSS produced significantly $(P<0.05)$ higher energy and protein digestibilities than HTSS. Results indicated that Nile tilapia can utilize the gross energy and crude protein of sorghum silage efficiently.

Key words: apparent digestibility, silage sorghum, Nile tilapia, tannin.

\section{INTRODUÇÃO}

A criação da tilápia do Nilo (Oreochromis niloticus) se encontra difundida em diversos países de clima tropical e subtropical. É uma das espécies mais promissoras para a piscicultura, apresentando bom desempenho em criações intensivas, além de possuir carne com boas características organolépticas e filés sem espinhos intramusculares em forma de "Y" (HILDSORF, 1995).

${ }^{1}$ Professores, Douores, Departamento de Zootecnia, Universidade Estadual de Maringá (UEM), Av. Colombo, 5790, 87020-900, Maringá-PR. E-mail: wmfuruya@uem.br. Autor para correspondência.

${ }^{2}$ Alunos do Curso de Graduação em Zootecnia, UEM. E-mail: lilianzoo@ hotmail.com

${ }^{3}$ Professor, Doutor, Departamento de Biologia, UEM. E-mail: chayashi@uem.br 
O milho é o cereal mais utilizado em rações no Brasil, mas tem sido substituído pelo sorgo em até $100 \%$ nas rações para monogástricos devido à semelhança de seus valores nutritivos. A substituição total do sorgo pelo milho é limitada devido a um fator antinutricional presente no sorgo, que é o tanino. A maior parte dos taninos presentes no sorgo pertence ao grupo dos condensados, que conferem baixa palatabilidade ao grão devido a seu sabor adstringente, além de formar complexos insolúveis com as proteínas, carboidratos (WARREHAM et al.,1994; QUINTERO et al., 2001; FREIRE, 2002) e outros nutrientes da ração (FIALHO \& PINTO, 1992; MUELLER-HARVEY \& McALLAN, 1992), afetando sua digestibilidade.

O uso de silagem de grão úmido em rações para monogástricos tem crescido no Brasil. A ensilagem de grãos permite aumento na digestibilidade do amido devido à sua gelatinização pelo aumento da temperatura e ação dos ácidos gerados durante o processo (JOBIM et al., 2001). Além disso, os taninos podem ser hidrolisados em açúcares durante a ensilagem melhorando o valor nutritivo do alimento (VAN SOEST, 1994).

Os coeficientes de digestibilidade aparente (CDA) da energia e proteína bruta foram determinados para diversas espécies de peixes. Recentemente, FURUYA et al. (2001) e PEZZATO et al. (2002) determinaram os CDA de diversos ingredientes pela tilápia do Nilo. No entanto, ainda são poucas as informações sobre o valor nutritivo da silagem de sorgo por essa espécie.

As espécies carnívoras apresentam baixa eficiência na utilização da energia dos grãos de cereais e seus subprodutos, o que está relacionado à sua menor capacidade de utilizar o amido destas fontes. Esta característica interfere na utilização dos demais nutrientes, por reduzir a ação das enzimas digestivas. Entre as espécies onívoras de água doce, as tilápias têm se destacado nos estudos de digestibilidade envolvendo fontes protéicas de origem vegetal (DEGANI \& REVACH, 1991). As tilápias utilizam eficientemente os carboidratos, por possuírem adaptações morfológicas e fisiológicas, tais como dentes faringeanos e intestino longo (KUBARIK, 1997).

Poucos são os trabalhos realizados com o objetivo de se determinar os CDA da energia e de proteína em tilápia do Nilo. Pela disponibilidade do sorgo em algumas regiões e menor custos em relação ao milho em determinadas épocas do ano, justificamse os estudos para se determinar a energia digestível e o CDA do sorgo desse ingrediente, visando reduzir o custo com alimentação. No presente trabalho, foram determinados os coeficientes de digestibilidade da energia e proteína bruta da silagem de sorgo, com alto e baixo tanino em tilápia do Nilo.

\section{MATERIALEMÉTODOS}

Este trabalho foi realizado no Laboratório de Aqüicultura da Universidade Estadual de Maringá - UEM, no período de 20 de julho a 09 de agosto de 2002. Foram utilizadas 42 tilápias do Nilo revertidas durante a fase larval, com peso vivo médio de 53,26 \pm $12,94 \mathrm{~g}$, alojadas em um aquário de fibra de vidro, com volume útil de 180L para a coleta de fezes (PEZZATO et al. 2002). O sistema foi mantido sob aeração constante através de pedra porosa acoplada a um soprador central, para manter o oxigênio entre 4 a $6 \mathrm{mg} /$ L. A temperatura da água foi mantida entre 25 e $27^{\circ} \mathrm{C}$. Estes parâmetros eram aferidos diariamente às $8 \mathrm{e} 17 \mathrm{~h}$ através de oximetro digital portátil para a leitura de oxigênio dissolvido e temperatura.

A renovação de água do aquário de coleta de fezes era realizada diariamente ( $8 \mathrm{~h} 30 \mathrm{~min}$ e $17 \mathrm{~h} 30 \mathrm{~min}$ ) utilizando-se água proveniente de um reservatório de $1.000 \mathrm{~L}$ com água mantida nas mesmas condições do aquário de digestibilidade.

Para a determinação dos CDA, foi utilizada uma ração referência (Tabela 1), a qual foi misturada aos ingredientes teste na proporção de 60:40. As silagens de sorgo baixo tanino $(0,44 \% / \mathrm{SSBT})$ e de sorgo de alto tanino $(1,14 \% / \mathrm{SSAT})$ foram ensiladas na Fazenda Experimental de Iguatemi, da Universidade Estadual de Maringá, de acordo com a metodologia descrita por JOBIM et al. (2001).

Para confecção das rações, após pesagem e homogeneização dos ingredientes, foi pulverizada água $\left(55^{\circ} \mathrm{C}\right)$ na proporção de $12 \%$ de seu peso total e, em seguida, peletizadas em moinho de carne e desidratada em estufa de ventilação forçada $\left(55^{\circ} \mathrm{C}\right)$, durante um período de $18 \mathrm{~h}$.

A coleta de fezes foi realizada diariamente às 8 e 17 h durante sete dias para formar um "pool" de amostras considerado como repetição. Para cada ração analisada, foram coletados três "pools" de fezes. Para a troca de ração foi estabelecido um intervalo de cinco dias para adaptação. O material coletado foi desidratado em estufa de ventilação forçada à temperatura de $55^{\circ} \mathrm{C}$ durante $24 \mathrm{~h}$. Após secagem, o material foi moído em moinho faca, identificado e armazenado em refrigerador para posterior análise.

Os peixes eram arraçoados em intervalos de duas horas, das $8 \mathrm{~h}$ às $17 \mathrm{~h}$, manualmente até saciedade aparente, em que não era observada captura dos grânulos fornecidos durante o seu deslocamento 
Tabela 1 - Composição percentual da ração referência.

\begin{tabular}{ll}
\hline Ingredientes & $\%$ \\
\hline Milho & 43,50 \\
Farelo soja & 40,00 \\
Glúten de milho & 10,00 \\
Fosfato bicálcico & 2,23 \\
Óleo de soja & 3,00 \\
L-lisina HCl & 0,30 \\
DL- metionina & 0,10 \\
Suplemento mineral e vitamínico & 0,50 \\
Vitamina C & 0,05 \\
Sal comum & 0,50 \\
BHT $^{3}$ & 0,02 \\
Alginato & 0,10 \\
Total $^{4}$ & 100,00 \\
\hline
\end{tabular}

${ }^{1}$ Suplemento mineral e vitamínico (Supremais): Composição por quilo de produto: Vit. A=1.200.000UI; vit. D3=200.000UI; vit. $\mathrm{E}=12.000 \mathrm{mg}$; vit. $\mathrm{K} 3=2.400 \mathrm{mg}$; vit. $\mathrm{B} 1=4.800 \mathrm{mg}$; vit. $\mathrm{B} 2=4.800 \mathrm{mg}$; vit. $\mathrm{B} 6=4.000 \mathrm{mg}$; vit. $\mathrm{B} 12=4.800 \mathrm{mg}$; ác. fólico $=1.200 \mathrm{mg}$; pantotenato de cálcio $=12.000 \mathrm{mg}$; vit. $\mathrm{C}=48.000 \mathrm{mg}$; biotina $=48 \mathrm{mg}$; colina $=65.000 \mathrm{mg}$; ácido nicotínico) $=24.000 \mathrm{mg} ; \quad \mathrm{Fe}=10.000 \mathrm{mg} ; \quad \mathrm{Cu}=600 \mathrm{mg} ; \quad \mathrm{Mn}=4.000 \mathrm{mg}$; $\mathrm{Zn}=6.000 \mathrm{mg} ; \mathrm{I}=20 \mathrm{mg} ; \mathrm{Co}=2 \mathrm{mg}$ e $\mathrm{Se}=20 \mathrm{mg}$.

${ }^{2}$ Vitamina $\mathrm{C}$ : sal cálcica 2-monofosfato de ácido ascórbico, $42 \%$ de princípio ativo.

${ }^{3}$ Butil-Hidroxi-tolueno.

${ }^{4}$ Aglutinante.

da superfície até o fundo dos aquários de alimentação. Os coeficientes de digestibilidade da energia e proteína bruta das rações foram determinados de acordo com a expressão proposta por NOSE (1960):

$C D A=100-\left[100 \cdot\left(\frac{\% I_{r}}{\% I_{f}}\right) \cdot\left(\frac{\% N_{f}}{\% N_{r}}\right)\right]$

Em que:

$\mathrm{CDA}=$ coeficiente de digestibilidade aparente $(\%)$;

$\% \mathrm{I}$ e $\% \mathrm{I}=\%$ Indicador na ração e nas fezes, respectivamente;

$\% \mathrm{~N}$ e $\% \mathrm{~N}=\%$ de nutriente nas fezes e na ração, respectivamente.

Cada ingrediente teste substituiu $40 \%$ da ração referência. Os CDA da energia e nutrientes dos alimentos foram calculados de acordo com a fórmula descrita por CHO \& SLINGER (1979):

$C D A=\frac{C D A_{D T}-C D A_{D R} \cdot x}{y}$

Em que:

CDADT $=$ coeficiente de digestibilidade aparente da energia ou nutrientes;
$\mathrm{CDA}=$ coeficiente de digestibilidade aparente da energia ou nutrientes na ração teste;

$\mathrm{CDA}^{\text {मR }}=$ coeficiente de digestibilidade aparente da energia ou nutrientes na ração referência;

$\mathrm{x}=$ proporção da ração referência;

$\mathrm{y}=$ proporção do ingrediente teste.

Como indicador inerte, foi utilizada a fibra em detergente neutro presente nas rações. As análises químico-bromatológicas da ração e das fezes foram realizadas no Laboratório de Análise de Alimentos do Departamento de Zootecnia da Universidade Estadual de Maringá - DZO/ UEM de acordo com a metodologia descrita por SILVA et al., (1990).

Os dados foram submetidos às análises de variância e os dados foram comparados pelo teste $t$, utilizando-se o programa SAEG (Sistemas de Análises Estatísticas e Genéticas) (EUCLYDES, 1983). O nível de significância utilizado para todos os dados foi déb $3 \%$.

\section{RESULTADOS E DISCUSSÃO}

Na tabela 2, encontra-se a composição química da ração referência e da SSBT e SSAT. Na tabela 3, encontram-se os valores dos CDA de energia e proteína bruta e de energia e proteína digestível da SSBT e SSAT. Os valores de energia digestível obtidos para os SSBT e SSAT foram ligeiramente superiores ao encontrado por PEZZATO et al. (2002), $(2779 \mathrm{kcal} / \mathrm{kg})$ para o sorgo baixo tanino não submetido ao processo de ensilagem. O processo de ensilagem permite aumentar a digestibilidade do amido dos grãos devido à gelatinização pelo aumento da temperatura e pela ação dos ácidos da silagem (JOBIM et al., 2001). Além disso, o processo de ensilagem pode hidrolisar os taninos em açúcares, reduzindo ou eliminando seus efeitos antinutricionais (VAN SOEST, 1994).

Tabela 2 - Composição química média da ração referência e da silagem de sorgo com baixo e alto tanino (base na matéria seca)*.

\begin{tabular}{llll}
\hline Composição & RR & SSBT & SSAT \\
\hline Matéria seca (\%) & 90,35 & 65,89 & 68,76 \\
Energia bruta (kcal/kg) & 4592,14 & 4346,00 & 4322,00 \\
Proteína bruta (\%) & 28,53 & 10,37 & 9,20 \\
Fibra bruta (\%) & 3,31 & 3,37 & 3,29 \\
Extrato etéreo (\%) & 6,11 & 3,17 & 2,65 \\
Cinzas (\%) & 6,07 & 5,83 & 6,26 \\
\hline
\end{tabular}

*Valores determinados em laboratório (LANA-UEM, Maringá PR).

RR =Ração referência; SSBT = silagem de sorgo baixo tanino e SSAT $=$ silagem de sorgo alto tanino. 
O CDA da energia bruta de SSBT foi superior ao de SSAT. Resultados semelhantes foram obtidos em estudo realizado com a tilápia do Nilo sobre a digestibilidade aparente de rações contendo sorgo alto e baixo tanino (FREIRE, 2002). Os valores menores de CDA da energia bruta do SSAT podem ser explicados pelo fato de que os taninos condensados afetam negativamente o valor nutricional dos alimentos devido à formação de complexos com os carboidratos (WARREHAM et al.,1994), e de inibirem a ação de algumas enzimas do trato digestório (FIALHO \& PINTO, 1992).

O CDA da proteína bruta do SSBT foi superior ao do SSAT, com valores de 2,5\% inferiores em relação ao do SSBT (Tabela 3). Estes resultados devem-se provavelmente aos efeitos negativos dos taninos sobre a proteína da ração, pois podem formar complexos insolúveis com essa proteína, e também sobre as enzimas proteolíticas. Além disso, alguns aminoácidos possuem grande afinidade pelos taninos, formando complexos que dificultam sua absorção durante o processo digestivo (MUELLER-HARVEY \& McALLAN, 1992).

A ação dos taninos sobre a digestibilidade de proteínas em tilápia do Nilo foi reportada por QUINTERO et al. (2001) em estudo que determinaram os CDA de rações contendo $0 ; 0,23 ; 0,46 ; 0,69 ; 0,92$; 1,37 e $1,82 \%$ de taninos totais obtidos do extrato de barbatimão. A utilização de ração com $0,46 \%$ de taninos totais reduziu o CDA da proteína bruta.

Os resultados dos CDA, apresentados neste estudo, mostraram que ambos, SSBT e SSAT, apresentam valores de energia digestível próximos aos obtidos com o milho por FURUYA et al. (2001) e PEZZATO et al. (2002), em estudo realizado com juvenis

Tabela 3 - Coeficiente de digestibilidade aparente (CDA) da energia e proteína bruta da ração referência e da silagem de sorgo baixo e alto tanino*.

\begin{tabular}{lcc}
\hline Composição & SSBT & SSAT \\
\hline Energia bruta & & \\
CDA (\%) & $70,17 \pm 0,12^{\mathrm{a}}$ & $68,37 \pm 0,09^{\mathrm{b}}$ \\
Energia digestível (kcal/kg) & $3049,81 \pm 3,70$ & $2954,74 \pm 2,81$ \\
Proteína bruta & & \\
CDA (\%) & $84,94 \pm 0,87^{\mathrm{a}}$ & $82,40 \pm 0,39^{\mathrm{b}}$ \\
Proteína digestível & $8,81 \pm 0,09$ & $7,58 \pm 0,04$ \\
\hline
\end{tabular}

* Valores determinados em laboratório (LANA-UEM, Maringá PR).

Letras diferentes em uma mesma linha indicam diferenças $(\mathrm{P}<0,05)$ pelo teste $\mathrm{t}$.

$\mathrm{SSBT}=$ silagem de sorgo baixo tanino e SSAT $=$ silagem de sorgo alto tanino. de tilápia do Nilo, de 3067 e 3316kcal de energia digestível $\mathrm{kg}^{-1}$, respectivamente. Assim, os SSBT e SSAT, em termos energéticos, podem ser utilizados como substitutos do milho. Por outro lado, devido à elevada influência dos taninos sobre o CDA da proteína bruta, a utilização de SSAT deve ser avaliada para evitar estes efeitos negativos sobre a utilização dos seus nutrientes.

As tilápias utilizam eficientemente a energia e os nutrientes de origem vegetal, sendo superiores à carpa e ao bagre do canal quanto à utilização de carboidratos (DEGANI \& REVACH, 1991). A melhor utilização de carboidratos pelas tilápias está relacionada às suas características morfológicas e fisiológicas (KUBARIK, 1997). O conhecimento dos CDA e dos valores de energia e proteína digestíveis de ingredientes alternativos ao milho permite a elaboração de rações mais precisas e de menor custo para viabilizar o retorno econômico. Os resultados obtidos no presente trabalho permitem incluir o sorgo em rações para a tilápia do Nilo. Entretanto, os níveis de taninos devem ser observados, bem como o aproveitamento de sorgo através da ensilagem, uma vez que os mesmos alteram a utilização da energia bruta e da proteína bruta da ração.

\section{CONCLUSÕES}

Os sorgos com baixo e alto e tanino possuem coeficientes de digestibilidade da energia bruta de $70,17 \%\left(3049,81 \mathrm{kcal}\right.$ de energia digestível $\left.\mathrm{kg}^{-1}\right) \mathrm{e}$ $68,37 \%\left(2954,75 \mathrm{kcal}\right.$ de energia digestível $\left.\mathrm{kg}^{-1}\right)$ e de proteína bruta de $84,94 \%(8,81 \%$ de proteína digestível) e $82,40 \%$ (7,58\% de energia digestível), respectivamente.

\section{REFERÊNCIAS BIBLIOGRÁFICAS}

CHO, C.Y; SLINGER, S.I. Apparent digestibility measurement in feedstuff for rainbow trout. In: WORD SYMPOSIUM ON FINFISH NUTRITION AND FISHFEED TECHNOLOGY, 1978, Hamburg. Proceedings... Heeneman : Halver, J. \& Tiews, K., 1979. p.239-247.

DEGANI, G.; REVACH, A. Digestive capabilities of three commensal fish species: carp, Cyprinus carpio L., tilápia, Oreochromis aureus x O. niloticus, and African catfish, Clarias gariepinus (Burchell, 1882). Aquaculture and Fischeries Management, v.22, p.397-403, 1991.

EUCLYDES, R.F. Manual de utilização do programa SAEG (Sistema para análises estatística e genética). Viçosa : UFV, 1983. 59p. 
FREIRE, E.S. Avaliação biológica de sorgo alto e baixo tanino por meio do desempenho e digestibilidade em tilápia do Nilo (Oreochromis niloticus). 2002. $65 \mathrm{f}$. Dissertação (Mestrado em Zootecnia) - Curso de Pós-graduação em Zootecnia, Universidade Estadual Paulista de Botucatu.

FIALHO, E.T.; PINTO, H. Utilização de sorgo em rações para suínos e aves. Concórdia, SC : Embrapa, 1992. V.16, p.4-19.

FURUYA, W.M. et al. Coeficientes de digestibilidade aparente da energia e nutrientes de alguns ingredientes pela tilápia do Nilo, Oreochromis niloticus (L.) (linhagem tailandesa). Acta Scientiarum, v.23, n.2, p.465-469, 2001

HILDSORF, A.W.S. Genética e cultivo de tilápias vermelhas, uma revisão. Boletim do Instituto de Pesca, v.22, p.73-87, 1995.

JOBIM, C.C.; CECATO, U.; CANTO, M.W. do. Utilização de Silagem de grãos de cereais na alimentação animal. In: SIMPÓSIO SOBRE PRODUÇÃO E UTILIZAÇÃO DE FORRAGENS CONSERVADAS, 2001, Maringá, Paraná. Anais... Maringá : UEM/CCA/DZO, 2001. V.1, 319p. p.146-176.

KUBARIK, J. Tilapia on highly flexible diets. Feed International, v.6, p.16-18, 1997

MUELLER-HARVEY, I.; MCALLAN, A.B. Tannins: their biochemistry and nutritional properties. Adv Plant Cell
Biochem Biotechnol, v.1, p.151-217. 1992.

NOSE, T. On the digestion of food protein by gold-fish (Carassius auratus L.) and rainbow trout (Salmo irideus G.). Bull Freshwater Fish Res Lab, v.10, p.11-22, 1960.

PEZZATO, L.E. et al. Digestibilidade aparente de ingredientes pela tilápia do Nilo (Oreochromis niloticus). Revista Brasileira de Zootecnia, v.31, n.4, p.1595-1604, 2002.

QUINTERO, P.L.G. et al. Desempenho do piauçu (Leporinus macrocephalus) arraçoado com dietas contendo diferentes níveis de tanino. Revista Brasileira de Zootecnia, v.30, n.4, p.1164-1171, 2001

SILVA, S.S. Análise de alimentos (métodos químicos e biológicos). 2.ed. Viçosa : UFV, 1990. 166p.

VAN SOEST, P.J. Nutritional ecology of the ruminant. New York : Cornell University, 1994. 476p.

WARREHAM, C.N.; WISEMAN, J.; COLE, D.J.A. Processing and antinutritive factors in feedstuffs. In: COLE, D.J.A.; VARLEY, M.A. Principles of pig sciences. Nottingham, 1994. 427p.

YAMAMOTO, T. et al. Apparent availabilities of amino acids and minerals from several protein sources for fingerling rainbow trout. Fisheries Science, v.63 n.6, p.995-1001, 1997. 